\title{
Organ-saving surgical alternatives to treatment of heart failure
}

\author{
Roland Hetzer ${ }^{1}$, Mariano Francisco del Maria Javier ${ }^{1}$, Frank Wagner ${ }^{2}$, Matthias Loebe ${ }^{3}$, \\ Eva Maria Javier Delmo ${ }^{2}$
}

${ }^{1}$ Department of Cardiothoracic and Vascular Surgery, Cardio Centrum Berlin, Berlin, Germany; ${ }^{2}$ Charité Research Organization, Universitätsmedizin Berlin-Charité, Berlin, Germany; ${ }^{3}$ Thoracic Transplant and Mechanical Support, Miami Transplant Institute, Memorial Jackson Health System, University of Miami, Miami, FL, USA

Contributions: (I) Conception and design: All authors; (II) Administrative support: None; (III) Provision of study materials or patients: All authors; (IV) Collection and assembly of data: All authors; (V) Data analysis and interpretation: All authors; (VI) Manuscript writing: All authors; (VII) Final approval of manuscript: All authors.

Correspondence to: Eva Maria Javier Delmo, MD, MSc, PhD. Universitätsmedizin Berlin-Charité, Charité Research Organization, Virchowweg 10, 10117 Berlin, Germany. Email: eva.javierdelmo@gmail.com.

\begin{abstract}
Over time, various surgical treatment strategies have evolved to manage advanced heart failure (HF). Scientific and technological breakthroughs through the last 50 years have put forward various surgical alternatives to patients with advanced $\mathrm{HF}$ encompassing surgical ventricular restoration to surgical gene therapy and stem cell replacement of the diseased ventricles. Organ-saving surgical options which used to be promising included dynamic cardiomyoplasty, partial resection of ventricle and cardiac wrapping with Acorn CorCap cardiac support device. These procedures were eventually abandoned due to negative outcomes and without proven disadvantages. Another organ-saving surgical option currently being considered but still make little sense is cardiac regeneration by stem cell therapy, i.e., cardiomyocyte restoration and replacement. Presently, the organ-saving surgical alternatives to treat end-stage HF are revascularization for ischemic cardiomyopathy, mitral valve surgery (repair or replacement) for ischemic mitral incompetence (IMI), left ventricular (LV) aneurysmectomy (surgical ventricular restoration) and mitral valve repair for IMI. These aforementioned procedures have become quite established approaches and with increasing experience are continuously being modified to improve outcome. Various mechanical circulatory support systems have emerged over time to improve functional status of patients with advanced HF, either as a bridge to heart transplantation or as a bridge to myocardial recovery. Likewise offered in those with contraindications to transplantation. Ventricular assist devices (VAD) can keep patients alive until an eventual transplantation. This article reviews the variety of the myriad of alternative organ-saving surgical alternatives that have been available or are currently available provided to patients with end-stage HF, their advantages and deficiencies, as well as prospects in HF therapy.
\end{abstract}

Keywords: Aneurysmectomy; cardiomyoplasty; coronary revascularization; heart failure (HF); heart transplantation; ischemic cardiomyopathy; ischemic mitral incompetence (IMI); partial left ventriculectomy; stem cell therapy; ventricular assist devices (VAD)

Submitted Feb 25, 2020. Accepted for publication Jun 29, 2020.

doi: $10.21037 / \mathrm{cdt}-20-285$

View this article at: http://dx.doi.org/10.21037/cdt-20-285

\section{Introduction}

Heart failure (HF) is a global pandemic disease affecting around 26 million people worldwide (1). The increased prevalence may not necessarily be correlated with an increase in HF incidence, which has been reported to be stable or even decreasing in several studies, particularly in women $(2,3)$. The aging of the population, together with improved HF survival due to the advancement in treatments and diagnostic technology, could explain the increase in 
prevalence. Moreover, the incidence reduction has been induced by several prevention schemes, hence lowering the severity and improving management of $\mathrm{HF}$ and improving management of acute coronary syndromes (4-7).

Altogether, the present health care delivery system still remains challenged with surging number of HF patients resistant to medical management and outbalanced the limits of heart transplantation. Scientific and technological breakthroughs through the last 50 years have put forward various surgical alternatives to this special subset of patients encompassing surgical ventricular restoration to surgical gene therapy and stem cell replacement of the diseased ventricles.

This article reviews the variety of organ-saving-surgical alternatives that have been available or are currently provided to patients with end-stage $\mathrm{HF}$, their advantages and deficiencies, as well as prospects in HF therapy. Heart transplantation and ventricular assist devices (VAD) will be discussed briefly, as these surgical treatments are thoroughly described elsewhere in this focus issue.

\section{Surgery for end-stage HF}

Outcomes of any surgical approach to treat advanced HF is largely dependent on the quantity and quality of the myocardial viability. Some patients may even necessitate further mechanical circulatory support either with shortterm extracorporeal membrane oxygenation or a VAD.

\section{Abandoned surgical options}

Dynamic cardiomyoplasty used to be a promising though unestablished surgical management in advanced HF. Carpentier and Chachques first introduced the technique of mobilizing the latissimus dorsi muscle to be wrapped around the heart circumferentially in 1985, and since then performed more than 1,500 procedures (8). The muscle wrap is conditioned for a certain period, after which contraction is stimulated to synchronize with systolic contraction. The repetitive muscle stimulations induce biochemical as well as physiological modifications, i.e., fatigue resistance, enhanced aerobic capacity, amplified contraction, decrease in size and maximized power reduction, to function as a myocardium (9-12). It was perceived as a cardiac support by mechanical compression during the ejection phase, hence increasing stroke volume, ejection fraction (EF) and cardiac output. The effective synchronized support of muscle wrapping on the failing heart has been shown in some reports (13-16). However, though an enhanced functional status has been demonstrated, there has been scarce valid evidences on its influence on hemodynamic improvement, if at all there is $(17,18)$. The principal effect of cardiomyoplasty was envisioned to hinder progressive ventricular remodeling $(17,19-21)$.

Acker (15) stated that the important albeit subtle effect of an attenuation of progressive cardiac enlargement accredited to angiotensin-converting enzyme inhibitors in patients with HF with a small but important survival benefit has been demonstrated in large prospective randomized trial (Study On Left Ventricular Dysfunction, SOLVD) (16). Thereafter, the Cardiomyoplasty-Skeletal Muscle Assist Randomized Trial (C-SMART) demonstrated in 1995 that although functional improvements were seen, there has been no significant hemodynamic or survival benefits gained. This study then provided a clearer picture that dynamic cardiomyoplasty has no adjunctive role as a rational surgical option. Justifiable skepticisms about the efficacy of dynamic cardiomyoplasty then have forever remained.

Many cardiologists and cardiac surgeons as well completely agreed with Leier who in his editorial issued a straightforward statement that those patients needing dynamic cardiomyoplasty do not survive the procedure and those who survived it, do not need the procedure at all (18).

\section{Partial resection of the ventricle-Batista operation}

In the mid-1990s, to overcome limitations of heart transplantation in HF treatment, the Brazilian surgeon Batista and coworkers (22) created an innovative and radical operation, named partial left ventriculectomy (PLV, Batista operation, Batista procedure) to as a penultimate option to treat patients with end-stage $\mathrm{HF}$ and as an alternative to heart transplantation. By using the concept of Laplace's law, where ventricular wall stress equals intracavity pressure $x$ radius $/ 2 \mathrm{x}$ wall thickness, the cornerstone was by reduction of the dilated ventricular chamber, its volume/mass ratio could be normalized. Then, the group hypothesized that decreasing left ventricular (LV) wall tension through volume reduction could lead to a decrease in wall stress and myocardial oxygen consumption, hence, improvement in systolic function. The procedure became well known internationally when he reported his experience at the Society of Thoracic Surgeons' meeting in 1997 (22) revealing that in 120 patients [New York Heart Association (NYHA) class IV] with dilated cardiomyopathy (DCMP) 
of various etiologies (ischemic, valvular, idiopathic viral or Chagas' disease) the 30-day mortality rate was $22 \%$ and the 2-year survival rate was $55 \%$. After PLV, approximately $90 \%$ of the surviving patients reverted back to NYHA class I or II.

Batista's lecture encouraged many cardiac surgeons in various countries to apply PLV to treat end-stage cardiomyopathy.

The initial results obtained with the PLV generated immense interest among surgeons worldwide (23-26) and more than 70 centers, at least 20 in Japan, performed PLV in the 1990s. They were all eager to increase their experience on PLV to decrease mortality. They have then shown that $25 \%$ of post-PLV patients lived without any cardiac-related adverse events within 3 years. They believed that PLV was a satisfactory surgical alternative that would save lives of selected patients waiting for transplantation.

However, the great enthusiasm subsided when clinical reports eventually implied that PLV was correlated with increased mortality, unrelenting symptoms of advanced HF, hence a greater need either of a heart transplantation or support with a VAD (27).

Thereafter the fame of PLV rapidly declined beginning in 2001 when the Cleveland group demonstrated convincing unfavorable outcomes and perioperative failures of PLV concluding that this surgery could only be offered in cases of contraindications to heart transplantation or as a bridge to heart transplantation (28). This has then led to the negation of the widespread performance of PLV. Consequently, the zest for the audacious PLV procedure waned, though a few institutions have continued to use it (29-33).

Since then, PLV was performed cautiously until it almost faded. Nevertheless, Suma (34), a Japanese surgeon, has persisted in applying the technique with modifications, i.e., selected ventriculoplasty for idiopathic DCMP, site selection (lateral, anteroseptal) of LV resection or segment exclusion in highly selected patients (34).

Hence, in Japan, ventricular restoration surgery, including more of a refined Batista procedure, has not perished and even has been considered a good nontransplant option for selected patients with end-stage DCMP. Curiously, in United States, the PLV was not completely discontinued, considering that in the period of 2008-2014 it was applied in 401 patients though has decreased over time and is presently offered in a highly limited number of selected patients (35).

\section{Acorn CorCap cardiac support device}

$\mathrm{HF}$ is characterized by major changes in cardiac structure and eventual cardiac dilatation leading to progressive decrease in myocardial function (36-41).

Progression of HF suggests that medications alone may not shield the decline in myocardial structure and function, hence, the search for innovative strategies continued. Surgical approaches which unload the ventricle have been greatly considered.

A surgical approach evolved through the introduction of the Acorn CorCap cardiac support device (CSD; Acorn Cardiovascular, Inc., St Paul, Minn.), a mesh-like woven polyester jacket that is surgically placed around in the heart circumferentially tailored to provide assistance during diastole. It is designed to decrease-wall stress-and myocyte overstretching and unloads the heart, thus ventricular remodeling (stretching of the myocardium) may be arrested and even be annulled.

Initial studies (42) in 48 patients supported with the device between April 1999 and April 2001 revealed a significant decrease in $\mathrm{LV}$ end-diastolic dimension (LVEDD), as early as 3 months post-implantation and further diminution at 6 months. The decrease in LVEDD was sustained during a 3-year follow-up, hence regarded as a remarkable support. The ejection fraction (EF) significantly increased at 3 months reaching an enhanced improvement at 6 months, and sustained within 3 years post-surgery. No manifestation of constriction was evident hemodynamically. These initial studies demonstrated that the device implantation was safe with no additional surgical adverse events.

$\mathrm{Oz}$ et al. (43) implanted the device with international colleagues worldwide, as part of a trial, in more than 130 patients with DCMP with or without simultaneous cardiac procedures. There was a $4.6 \%$ mean intraoperative reduction in LVEDD and there were neither device-related intraoperative complications and adverse events nor evident constrictive physiology with maintenance of coronary artery flow reserve, decrease of ventricular size and improvement in EF and NYHA functional class during a 2-year followup. Survival rates were $73 \%$ and $68 \%$ at 12 and 24 months, respectively. The group involved in the said trial confirmed the safety of the Acorn CorCap CSD device in patients with DCMP. Further randomized clinical trials have been performed then in Europe, Australia, and North America (44-47). These studies then concluded that the Acorn CorCap CSD was a promising surgical therapy for DCMP. 
The most commonly cited concern about the Acorn CorCap CSD implantation was then the late development of pericardial constriction. However, in a report by Mann et al. (48) during the 5-year follow-up, there have been no cases of pericardial constriction detected during the 5 -year follow-up.

Nonetheless, the long-term effects of the Acorn CorCap CSD on myofiber stress and ventricular function remained largely unknown and unreported. Further device trials have been disapproved by the FDA in 2008 based on the following issues: (I) NYHA class results are not clinically significant (49), (II) no survival difference between treatment and control groups (49), (III) high perioperative mortality in no-MVR group (49), (IV) severe adhesions and fibrosis (49).

Hence, with the formidable concerns over the long-term pericardial constriction from the excessive adhesions and which could exacerbate HF (49), the device was completely withdrawn from the market.

\section{Surgical options that still makes little sense}

\section{Stem cell therapy (cardiomyocyte restoration and replacement)}

Persistent cardiomyocyte loss due to myocardial infarction and apoptosis are the hallmarks of most etiologies of HF. Various strategies aimed at augmenting the amount functioning cardiomyocytes have been conceived to improve the course of this disease. Eventually, encouraging results from animal studies led to an explosion of research and clinical trials for stem cell therapy emerged during the past decade, aiming to promote therapeutic myocardial regeneration and repair, but outcomes thus far have been modest (50).

Ceaseless disagreements on where to get the optimal cells, how to process and deliver them as well as when and how to transfer them to the heart as well as several cellular issues, i.e., delivering or using autologous skeletal myoblasts, mobilization of bone marrow progenitors, direct delivery of unfractionated bone marrow cells or specific marrow-derived cells, delivery of cardiac-derived stem cells, cardiac tissue engineering, promoting differentiation and maturation of cardiac progenitors and fostering integration with the host myocardium. Clinical trials to date support the safety of cardiac delivery of stem/progenitor cells. However, augmenting the cellular amount is not enough to enhance the endogenous repair processes after myocardial infarction and has relatively minor overall impact (51).

Thereafter, multiple preclinical and clinical studies have reported use of various types of stem cells delivered through varying routes $(52,53)$. While most of these studies chronicled positive results, some appropriate concerns were raised in others. This has catalyzed a considerable uncertainty regarding stem cell therapy and an inability to formulate therapeutic recommendations. These are another disappointment in HF, especially after the retraction of several stem-cell studies from the laboratory of one defamed investigator (52). The lack of evidence has not stopped fraud in promoting stem cells for HF (54).

Consequently, the search for strategies focused on stem cell-based therapies to durably restore ventricular function continued (55). However, subsequent researches suggested that stem cells do not differentiate into functional cardiomyocytes.

Presently, small and inconsistent evidences of any clinical benefit of stem cell therapy for HF with reduced EF has been acknowledged. The study by Yau et al. (56) on 106 patients is another example of a negative study in a largely disappointing spectrum of cell-based research. This study provided further evidence that mesenchymal precursor cells injected into the myocardium may not be the widely sought alternative therapy in advanced HF due to DCMP.

Given these generally negative results, the European Society of Cardiology Working Group concluded that the promise of cell therapy has not yet been fulfilled (57). The recent disclosure that the research of one of the pioneers of cell-based therapy, was largely fraudulent, has besmirched this field (58).

Steinhoff et al. $(59,60)$ equally stated that the concept of stem cell therapy is still far from its clinical application despite a two-decade exhaustive research and efforts to translate stem cell approach to treat cardiac diseases. The group pointed out that the main outcome in clinical use of stem cell therapy does not reflect experimental evidence. $\mathrm{He}$ and his group tried to schematize the hindrances and concentrations on the fundamental processes as the basis for regenerative medicine. They surmised that the lack of knowledge homogenization from tissue repair and mechanism of diseases is the main impediment to success. Furthermore, the group advocated that utilizing artificial intelligence through machine learning and centralized sharing of open-access data might ultimately be a pivotal point with regard to having a profound comprehension about the intricate system of cardiac regeneration. 


\section{Current treatment strategies}

\section{Ischemic cardiomyopathy revascularization}

Dysfunction of the left ventricle from a myocardial infarction in patients with coronary artery disease (CAD) may still be reversible. In fact, there is a substantial improvement of LV function in many patients and may even revert to normal after coronary artery bypass grafting (CABG) (61-63).

Velasquez et al. (64) reported the results of their study conducted between July 2002 and May 2007 in 1,212 patients with a CAD amenable to CABG and $\mathrm{EF}$ of $\leq 35 \%$, randomly assigned to optimal medical therapy (OMT) alone (602 patients) or OMT + CABG (610 patients). In this randomized trial, no significant difference between the two groups was demonstrated in terms of mortality from any cause, with those who underwent CABG having lower mortality and hospitalization rates from cardiovascular causes.

The landmark Surgical Treatment for Ischemic Heart Failure (STICH) trial, investigated the superiority of CABG + OMT over OMT alone and the superiority of CABG + surgical ventricular reconstruction (SVR) over CABG alone, in $\mathrm{CAD}$ amenable to revascularization. The 10 -year followup outcome demonstrated significant long-term benefits with $\mathrm{CABG}+\mathrm{OMT}(65,66)$.

No difference between CABG + SVR and SVR alone has been illustrated. The STICH trial and the other subsequent multiple studies have substantiated and disputed numerous general viewpoints in the treatment of patients with severe LV dysfunction and ischemic HF $(65,66)$. Although the reported outcomes exemplify an explicit data presently on hand, they have been correlated with several debatable issues, i.e., the lack of benefit of SVR (67), the lack of 5 -year survival benefit between CABG and OMT (64) the lack of survival benefits of CABG on patients with viable myocardium (68) or with angina (69) and the improved outcomes of CABG on patients with larger ventricles and lower LVEF (70), whereby disputing the usual clinical practice, presuppositions and pathophysiological cognizance (71-73). Since medical therapy is a key constituent in management of ischemic cardiomyopathy, the intricate results cannot simply extrapolate that coronary revascularization provides no survival advantage, that surgical ventricular restoration is futile and myocardial viability and angina are insignificant. This may then be rationalized to an imperfect study design, patient selection, data analysis and interpretation, substandard follow-up, and inadequate decrease in $\mathrm{LV}$ volumes. The STICH trial has provided elemental albeit flawed information, hence, adding confusion in treating this subset of patients.

In our experience (74), coronary revascularization in patients with ischemic cardiomyopathy is highly valid in hibernating myocardium without apoptosis and scarring, frequently in combination with acute and chronic infarct sequelae. A good LV wall thickness on echocardiography ( $>8$ $\mathrm{mm}$ ) without infarction is an impeccable index of viability. A severe proximal obstruction of coronary arteries and sufficient peripheral vessel branches justify a satisfactory outcome of CABG.

\section{LV aneurysmectomy (SVR) in ischemic HF}

A LV aneurysm is any akinetic (no motion during systole) or dyskinetic (appears to bulge paradoxically during systole) segment of myocardium associated with a reduced $\mathrm{LV}$ EF (75). Intraoperatively, the aneurysm is identified as a circumscribed area of scar, which is thin, often adherent to the pericardium and which may or may not bulge paradoxically during systole and the aneurysmal segment is easily outlined by looking for the area that puckers and collapses when the LV is vented (76). Favaloro and colleagues (77) described it as a full-thickness scar-tissue replacement of the $\mathrm{LV}$ wall, typically with-thrombus adherently fixed to the pericardium.

Likoff (78) performed the first successful LV aneurysmectomy in a human being. Since then, with cardiopulmonary bypass and improved surgical techniques, aneurysmectomy has become an established procedure in patients with LV aneurysms and severe symptoms.

These approaches done on dysfunctional dilated hearts entail resection of an area of the $L V$ wall to reduce the ventricular circumference. The Batista technique (22) the endoventricular circular patch repair introduced by Dor $(79,80)$, and several repair techniques of ventricular aneurysm and rendered by Cooley $(81,82)$ and Jatene (83) exemplify the significant technical modifications including selection of patients.

As interest in Batista's technique receded, great attention was given to volume reduction surgical procedures in selected patients after myocardial infarction (84-87). In contrast to Batista's removal of functional myocardium, ventricular volume reduction entails resection or exclusion of stiff segments of akinetic scar or relatively compliant dyskinetic scar (71,72,81-83). However, though there is an acceptance to surgically treat dyskinetic scar, there has been 
disagreement on exclusion of akinetic wall areas concerning its physiological effects.

As previously mentioned, the National Heart, Lung, and Blood Institute-sponsored STICH randomized trial showed that the addition of SVR to CABG provided no benefit in overall survival or survival free from cardiac hospitalization compared with CABG alone (66). However, Jones et al. (67) commented that the STICH trial may have failed to show an improvement in survival with SVR because the surgery did not make the ventricle small enough, or the aneurysm was too small.

Based on our experience following Cooley's concept $(81,82)$, SVR is highly beneficial in patients with advanced $\mathrm{HF}$ and optimal in a localized and thin-walled aneurysm without involvement of the other coronary artery complex and dependent on the status of the residual viable myocardium. A combined view of CT motion scans and echo strain rate to assess the indication for and dimensions of ventricular reduction have been a reliable diagnostic modality.

\section{Mitral valve repair for ischemic mitral incompetence (IMI)}

IMI is a known complication of end-stage cardiomyopathy and is associated with a poor prognosis. It is an intricate CAD-related heterogenous disease, usually occurring after myocardial infarction, and is associated with poor prognosis (88). It encompasses global and regional LV remodeling including-dysfunction and distortion of the mitral valve (MV) and its subvalvar apparatus. Moreover, the dyskinetic/akinetic ventricular wall bearing the papillary muscles leads to restriction of leaflet mobility; hence, resulting to extension of the distance between the ventricular wall and the leaflets. These modifications lead to failure of leaflet coaptation, thus, mitral insufficiency ensues (89). Historically, these patients were managed medically and frequently with MV replacement, both of which have unfavorable long-term outcomes.

Reduction of the annulus with an undersized ring has once appeared to be the preferred surgical option to correct IMI $(90,91)$. However, various institutions chronicled their experiences on significant residual and recurrence rates of moderate to severe mitral incompetence in $30 \%$ of patients within 6 months of surgery $(92-96)$. Some reported $(97,98)$ ring annuloplasty may even exacerbate the abnormal leaflet geometry, i.e., augmentation of leaflet tethering, decreasing the leaflet curvature and increasing the leaflet and chordal stress, thus, rendering suboptimal repair results for IMI. These concerns have paved emergence of various sub-valvular and leaflet techniques such as cutting of the secondary chordae (99), papillary muscle modification (100), augmentations of posterior leaflet (101-104) and anterior leaflet (105). Apparently, the aforementioned-techniques were used in small cohorts, and long-term outcome should still be appraised.

Basically, IMI is surgically managed with CABG with or without concomitant MV repair using either diverse techniques of MV repair (annuloplasty using sutures, bands, rings) or MV replacement (106-111). In the late 1990s, our group $(112,113)$ reported that patients with highly impaired LV function and IMI are at high risk during MV repair or replacement, and these options should be offered only in patients with IMI with moderately impaired LV function. Based on our experience, we then advocated that if MV repair could not reduce insufficiency to at least grade 1 , then the valve should be replaced during the same operation.

Since IMI is basically an aftermath of a ventricular malaise rather than a valvular lesion itself, our group $(114,115)$ patronized the posterior leaflet augmentation technique, a surgical strategy conceived to address the IMI from lack of anterior and posterior leaflet coaptation on their posterior regions. A piece of fresh native pericardium to stabilize the shortened posterior annulus strengthens the repair and promotes preservation of the MV geometry, abates the tethering of sub-valvular apparatus and reduces the interpapillary muscle distance. The geometrical restoration thus facilitates improvement in LV function.

In our series of 75 patients (115), the frequency of remaining or recurring mitral incompetence is minimal. Decreasing the posterior annular diameter reinforced with a strip of fresh native pericardium brings the posterior and anterior leaflets near each other. It is a genuine and an easily performed maneuver which is valid and feasible to make the valve competent

\section{LOCIMAN}

End-stage HF consists of three main components such as regional myocardial ischemia as a sequela of coronary artery obstruction, LV aneurysm as a sequela of previous infarction and ischemic mitral incompetence as a consequence of ventricular dilatation. We then coined the syndrome LOCIMAN, which stands for Left ventricular failure, Obstruction of Coronary arteries, Ischemic Mitral incompetence and left ventricular Aneurysm.

We have 314 patients with all these components of HF. 
Surgical strategies consisted of performing CABG, MV repair and replacement (depending on LVEF, range, 15$40 \%$ ) and LV aneurysmectomy. The 1-, 5-, 10- and 15-year survival were acceptable and increased improvement in NYHA Functional class were observed (yet unpublished data).

In considering surgical treatment for this syndrome, the questions we have raised are: (I) what is the pertinent involvement of hibernating myocardium, IMI, aneurysm/ akinesia to LV failure and (II) what is the relative benefit of coronary artery bypass, mitral repair and ventricular restoration/aneurysmectomy?

\section{Heart transplantation}

Heart transplantation is the gold standard treatment in patients with end-stage HF. However, quality of life by side effects of immunosuppressants, heightened occurrence of tumors, and development of chronic allograft vasculopathy. Likewise, the availability of donor heart is unpredictable. Its procurement involves a complex organization of explantation and organ transport. Moreover, the quality of donor heart varies and cannot be reliably determined. Currently, with continued decline of organ donation, the procedure is infrequently offered, hence other alternatives may have to be sought.

\section{VAD}

VAD can keep patients alive until transplantation. In selected patients, especially with myocarditis and dilative cardiomyopathy, mechanical unloading can lead to myocardial recovery. However, as yet there are no reliable predictive criteria.

Various mechanical circulatory support systems have emerged over time to improve functional status of patients with advanced HF and also offered in those with contraindications to transplantation. Based on our experience, several patients even prefer a VAD over heart transplantation.-

Age per se should not be considered a contraindication for VAD implantation. Older patients who are intellectually capable of handling VAD, who have a strong will to live and who show good compliance may gain significant benefit from a VAD. An acceptable daily living is possible with a modern rotary pump. In a quite substantial proportion of HF patients (30\% or more) the implantation of two rotary pumps can now be offered also for the older patient group.
Several VADs have been proven to offer patients mobility and a good quality of life for $>5$ years. Permanent implants, VAD or total artificial heart is the ultimate goal of development of mechanical circulatory systems. Improvements need to be introduced with respect to thrombogenicity and energy transfer through the intact skin, pulsatility and remote monitoring. With rapidly increasing number of patients with chronic HF, VAD implantation is becoming a widespread routine procedure.

Within a quarter century, VAD implantation has grown from an experimental procedure to an established and generally accepted therapy. Today this should not be denied elderly patients.

Facing the rapidly increasing population of older patients with end-stage $\mathrm{HF}$, the use of VAD technology may be the most advanced progress in cardiac care of the coming years.

\section{Summary}

HF is a global pandemic disease affecting around 26 million people worldwide. Improved survival has been achieved due to the advancement in treatments and diagnostic technology. Altogether, the present health care delivery system still remains challenged with surging number of HF patients resistant to medical management and outbalanced the limits of heart transplantation, considered today as the most definitive treatment of HF. Donor organ scarcity led to continuing search for valid treatment options. Scientific and technological breakthroughs through the last 50 years have put forward various surgical alternatives to this special subset of patients.

Organ-saving surgical options which used to be promising included dynamic cardiomyoplasty, partial resection of ventricle and cardiac wrapping with Acorn CorCap cardiac support device. These procedures were eventually abandoned due to negative outcomes and without proven disadvantages.

Another organ-saving surgical option currently being considered but still make little sense is cardiac regeneration by stem cell therapy, i.e., cardiomyocyte restoration and replacement. Numerous intensive animal experiments and research have been going on in regeneration therapy and some apparent positive results of possible cardiomyocyte replacement have been tried in humans. However, the initial clinical applications have been clouded with controversies. It seems that as of today, myocyte replacement has not yet fulfilled its promise and still far away from its intended utilization. 
Presently, the organ-saving surgical alternatives to treat end-stage HF are revascularization for ischemic cardiomyopathy, mitral valve surgery (repair or replacement) for ischemic mitral incompetence, $\mathrm{LV}$ aneurysmectomy (surgical ventricular restoration) and mitral valve repair for ischemic mitral incompetence. These aforementioned procedures have become quite established procedures and with increasing experience are continuously being modified to improve outcome.

End-stage HF may present as regional myocardial ischemia, a sequela of coronary artery obstruction, $\mathrm{LV}$ aneurysm from previous infarction and ischemic mitral incompetence as a consequence of ventricular dilatation. We then coined the syndrome LOCIMAN, which stands for left ventricular failure, obstruction of coronary arteries, ischemic mitral incompetence and left ventricular aneurysm. To consider surgical treatment for this syndrome, the questions we have raised are the pertinent involvement of hibernating myocardium, IMI, aneurysm/akinesia to $\mathrm{LV}$ failure and the relative benefit of coronary artery revascularization, mitral repair and ventricular restoration/ aneurysmectomy.

Various mechanical circulatory support systems have emerged over time to improve functional status of patients with advanced HF and likewise offered in those with contraindications to transplantation. VAD can keep patients alive until transplantation. Several patients even prefer a VAD over transplantation. In selected patients, especially with myocarditis and dilative cardiomyopathy, unloading the left ventricle can lead to myocardial recovery. However, there are no reliable criteria to predict recovery.

\section{Acknowledgments}

Funding: None.

\section{Footnote}

Provenance and Peer Review: This article was commissioned by the editorial office, Cardiovascular Diagnosis and Therapy for the series "Heart Failure in the Young and Old: Insights into Various Therapies". The article has undergone external peer review.

Conflicts of Interest: The authors have completed the ICMJE uniform disclosure form (available at http://dx.doi. org/10.21037/cdt-20-285). The series "Heart Failure in the Young and Old: Insights into Various Therapies" was commissioned by the editorial office without any funding or sponsorship. RH served as the unpaid Guest Editor of the series, and serves as an unpaid editorial board member of Cardiovascular Diagnosis and Therapy from Jul 2019 to Jun 2021. The authors have no other conflicts of interest to declare.

Ethical Statement: The authors are accountable for all aspects of the work in ensuring that questions related to the accuracy or integrity of any part of the work are appropriately investigated and resolved.

Open Access Statement: This is an Open Access article distributed in accordance with the Creative Commons Attribution-NonCommercial-NoDerivs 4.0 International License (CC BY-NC-ND 4.0), which permits the noncommercial replication and distribution of the article with the strict proviso that no changes or edits are made and the original work is properly cited (including links to both the formal publication through the relevant DOI and the license). See: https://creativecommons.org/licenses/by-nc-nd/4.0/.

\section{References}

1. Savarese G, Lund LH. Global public health burden of heart failure Card Fail Rev 2017;3:7-11.

2. Ponikowski P, Anker SD, AlHabib KF, et al. Heart failure: preventing disease and death worldwide. ESC Heart Failure 2014;1:4-25.

3. Najafi F, Jamrozik K, Dobson AJ. Understanding the 'epidemic of heart failure': a systematic review of trends in determinants of heart failure. Eur J Heart Fail 2009;11:472-9.

4. Levy D, Kenchaiah S, Larson MG, et al. Long-term trends in the incidence of and survival with heart failure. $\mathrm{N}$ Engl J Med 2002;347:1397-402.

5. Heidenreich PA, Albert NM, Allen LA, et al. American Heart Association Advocacy Coordinating Committee; Council on Arteriosclerosis, Thrombosis and Vascular Biology; Council on Cardiovascular Radiology and Intervention; Council on Clinical Cardiology; Council on Epidemiology and Prevention; Stroke Council. Forecasting the impact of heart failure in the United States: a policy statement from the American Heart Association. Circ Heart Fail 2013;6:606-19.

6. Journath G, Hammar N, Elofsson S, et al. Time trends in 
incidence and mortality of acute myocardial infarction, and all-cause mortality following a cardiovascular prevention program in Sweden. PLoS One 2015;10:e140201.

7. Roger VL, Weston SA, Redfield MM, et al. Trends in heart failure incidence and survival in a community-based population. JAMA 2004;292:344-50.

8. Carpentier A, Chachques JC. Myocardial substitution with a stimulated skeletal muscle: first successful clinical case [Letter]. Lancet 1985;1:1267.

9. Mannion JD, Bitto T, Hammond RL, et al. Histochemical and fatigue characteristics of conditioned canine latissimus dorsi muscle. Circ Res 1986;58:298-304.

10. Salmons S, Sreter FA. Significance of impulse activity in the transformation of skeletal muscle type. Nature 1976;263:30-4.

11. Streter FA, Gergely J, Salmons S, et al. Synthesis by fast muscle of myosin light chains characteristic of slow muscle in response to long-term stimulation. Nat New Biol 1973;241:17-9.

12. Clark BJ, Acker MA, McCully K, et al. In vivo 31P-NMR spectroscopy of chronically stimulated canine skeletal muscle. Am J Physiol 1988;254:C-258-66.

13. Jatene AD, Moreira LF, Stolf NA, et al. Left ventricular function changes after cardiomyoplasty in patients with dilated cardiomyopathy. J Thorac Cardiovasc Surg 1991;102:132-8.

14. Schreuder JJ, van der Veen FH, van der Velde ET, et al. Beat-to-beat analysis of left ventricular pressure-volume relation and stroke volume by conductance catheter and aortic Modelflow in cardiomyoplasty patients. Circulation 1995;91:2010-7.

15. Acker MA. Acker, Dynamic Cardiomyoplasty: At the Crossroads. Ann Thorac Surg 1999;68:750-5.

16. Cohn JN. Structural basis for heart failure: ventricular remodeling and its pharmacologic inhibition. Circulation 1995; 91:2504-7.

17. Kass DA, Baughman KL, Pak PH, et al. Reverse remodeling from cardiomyoplasty in human heart failure. Circulation 1995;91:2314-8.

18. Leier CV. Cardiomyoplasty: is it time to wrap it up [Editorial]? J Am Coll Cardiol 1996;28:1181-2.

19. Hagège AA, Desnos $M$, Fernandez $F$, et al. Clinical study of the effect of latissimus dorsi muscle flap stimulation after cardiomyoplasty. Circulation 1995;92:II210-5.

20. Capouya ER, Gerber RS, Drinkwater DC Jr, et al. Girdling effect of nonstimulated cardiomyoplasty on left ventricular function. Ann Thorac Surg 1993;56:867-70.

21. Lorusso R, Milane E, Volterrani M, et al. Cardiomyoplasty as an isolated procedure to treat refractory heart failure. Eur J Cardiothorac Surg 1997;11:363-72.

22. Batista RJV, Verde J, Nery P, et al. Partial left ventriculectomy to treat end-stage heart disease. Ann Thorac Surg 1997;64:634-8.

23. McCarthy PM, Starling RC, Wong J, et al. Early results with partial left ventriculectomy. J Thorac Cardiovasc Surg 1997;114:755-63.

24. Angelini GD, Pryn S, Mehta D, et al. Left-ventricularvolume reduction for end-stage heart failure. Lancet 1997;350:489.

25. Gradinac S, Miríc M, Popovi'c Z, et al. Partial left ventriculectomy for idiopathic dilated cardiomyopathy: Early results and six-month follow-up. Ann Thorac Surg 1998;66:1963-8.

26. Moreira LFP, Stolf NAG, Bocchi EA, et al. Partial left ventriculectomy with mitral valve preservation in the treatment of patients with dilated cardiomyopathy. J Thorac Cardiovasc Surg 1998;115:800-7.

27. Starling RC, McCarthy PM. Partial left ventriculectomy: sunrise or sunset? Eur J Heart Fail 1999;1:313-7.

28. Franco-Cereceda A, McCarthy PM, Blackstone EH, et al. Partial left ventriculectomy for dilated cardiomyopathy: is this an alternative to transplantation? J Thorac Cardiovasc Surg 2001;121:879-93.

29. Wilhelm MJ, Hammel D, Schmid C, et al. Partial left ventriculectomy and mitral valve repair: Favorable shortterm results in carefully selected patients with advanced heart failure due to dilated cardiomyopathy. J Heart Lung Transplant 2005;24:1957-64.

30. Koyama T, Nishimura K, Soga Y, et al. Importance of preserving the apex and plication of the base in left ventricular volume reduction surgery. J Thorac Cardiovasc Surg 2003;125:669-77.

31. Suma H, Isomura $T$, Horii $T$, et al. Isolated effect of partial left ventriculectomy for dilated cardiomyopathy: A case report. J Cardiol 1999;33:273-7.

32. Dowling RD, Koenig SC, Ewert DL, et al. Acute cardiovascular changes of partial left ventriculectomy without mitral valve repair. Ann Thorac Surg 1999;67:1470-2.

33. Konertz W, Khoynezhad A, Sidiropoulos A, et al. Early and intermediate results of left ventricular reduction surgery. Eur J Cardiothorac Surg 1999;15:S26-30. 
34. Suma H. Partial left ventriculectomy. Circ J 2009;73:A19-22.

35. Roy SD, Taduru SS, Taneja A, et al. Recent trends in surgical management of heart failure in the united states. J Card Fail 2017;23:S122.

36. Baig MK, Mahon N, McKenna WJ, et al. The pathophysiology of advanced heart failure. Heart Lung 1999;28:87-101.

37. Chien KR. Stress pathways and heart failure. Cell 1999;98:555-8.

38. Goldstein S, Ali AS, Sabbah H. Ventricular remodeling. Cardiol Clin 1998;16:623-32.

39. Florea VG, Mareyev VY, Samko AN, et al. Left ventricular remodelling: common process in patients with different primary myocardial disorders. Int J Cardiol 1999;68:281-7.

40. Lee TH, Hamilton MA, Stevenson LW, et al. Impact of left ventricular cavity size on survival in advanced heart failure. Am J Cardiol 1993;72:672-6.

41. Vasan RS, Larson MG, Benjamin EJ, et al. Left ventricular dilatation and the risk of congestive heart failure in people without myocardial infarction. N Engl J Med 1997;336:1350-5.

42. Starling RC, Jessup M. Worldwide clinical experience with the CorCap Cardiac Support Device. Review J Card Fail 2004;10:S225-33.

43. Oz MC, Konertz WF, Kleber FX, et al. Global surgical experience with the Acorn cardiac support device. J Thorac Cardiovasc Surg 2003;126:983-91.

44. Konertz WF, Shapland JS, Hotz H, et al. Passive containment and reverse remodeling by a novel textile cardiac support device. Circulation 2001;104:1270-5.

45. Raman JS, Hata M, Storer M, et al. The mid-term results of ventricular containment (ACORN WRAP) for endstage ischemic cardiomyopathy. Ann Thorac Cardiovasc Surg 2001;7:278-81.

46. Kleber FX, Sonntag S, Krebs H, et al. Follow-up on passive cardiomyoplasty in congestive heart failure: influence of the Acorn ${ }^{\circledR}$ Cardiac Support Device on left ventricular function. J Am Coll Cardiol 2001;37:143A.

47. Chaudhry PA, Mishima T, Sharov VG, et al. Passive epicardial containment prevents ventricular remodeling in heart failure. Ann Thorac Surg 2000;70:1275-80.

48. Mann DL, Kubo SH, Sabbah HN, et al. Beneficial effects of the CorCap Cardiac Support Device: 5 year results from the Acorn trial. J Thorac Cardiovasc Surg 2012;143:1036-42.

49. FDA. Medical Devices Dispute Resolution Panel Meeting.
Briefing Information Vol I.H: History of Events for IDE G990267. December 15, 2006. Available online: https:// www.citizen.org/sites/default/files/2006-4269b1_17_fda.pdf

50. Broughton, KM, Wang BJ, Firouzi F, et al. Mechanisms of cardiac repair and regeneration. Circ Res 2018;122:1151-63.

51. Codina M, Elser J, Margulies KB. Current status of stem cell therapy in heart failure. Curr Cardiol Rep 2010;12:199-208.

52. Goff ZD, Kichura AB, Chibnall JT, et al. A survey of unregulated direct-to-consumer treatment centers providing stem cells for patients with heart failure. JAMA Intern Med 2017;177:1387-8.

53. Ghiroldi A, Piccoli M, Ciconte G, et al. Regenerating the human heart: direct reprogramming strategies and their current limitations. Basic Res Cardiol 2017;112:68.

54. Curfman G. Stem cell therapy for heart failure: An unfulfilled promise? JAMA 2019;321:1186-7.

55. Braunwald E. Cell-based therapy in cardiac regeneration: an overview. Circ Res 2018;123:132-7.

56. Yau TM, Pagani FD, Mancini DM, et al. Effect of intramyocardial injection of mesenchymal precursor cells on successful temporary weaning from left ventricular assist device support among patients with advanced heart failure: a randomized clinical trial. JAMA 2019;321:1176-86.

57. Madonna R, Van Laake LW, Davidson SM, et al. Position Paper of the European Society of Cardiology Working Group Cellular Biology of the Heart: cell-based therapies for myocardial repair and regeneration in ischemic heart disease and heart failure. Eur Heart J 2016;37:1789-98.

58. Retraction Watch. Anversa cardiac stem cell lab earns 13 retractions. Available online: https://retractionwatch. com/2018/12/13/anversa-cardiac-stem-cell-lab-earns-13retractions. Posted December 13, 2018. Accessed March 1, 2019.

59. Steinhoff G. Re-growth of the adult heart by stem cells? Eur J Cardiothorac Surg 2014;45:6-9.

60. Steinhoff G, Nesteruk J, Wolfien M, et al. Stem cells and heart disease - brake or accelerator? Adv Drug Deliv Rev 2017;120:2-24.

61. Dilsizian V, Bonow RO. Current diagnostic techniques of assessing myocardial viability in hibernating and stunned myocardium. Circulation 1993;87:1-20. Erratum, Circulation 1993;87:2070.

62. Allman KC, Shaw LJ, Hachamovitch R, et al. Myocardial viability testing and impact of revascularization on prognosis in patients with coronary artery disease and left 
ventricular dysfunction: a meta-analysis. J Am Coll Cardiol 2002;39:1151-8.

63. Elefteriades JA, Tolis G Jr, Levi E, et al. Coronary artery bypass grafting in severe left ventricular dysfunction: excellent survival with improved ejection fraction and functional state. J Am Coll Cardiol 1993;22:1411-7.

64. Velazquez EJ, Lee KL, Deja MA. Coronary artery bypass surgery in patients with left ventricular dysfunction. N Engl J Med 2011;364:1607-16.

65. Hassanabad AF, Kelsey T, MacQueen KT, et al. Surgical treatment for ischemic heart failure (STICH) trial: A review of outcomes. J Card Surg 2019;34:1075-82.

66. Michler RE, Rouleau JL, Al-Khaidi HR, et al. Insights from the STICH trial: change in left ventricular size after coronary artery bypass grafting with and without surgical ventricular reconstruction. J Thorac Cardiovasc Surg 2013;146:1139-45.e6.

67. Jones RH, Velazquez EJ, Michler RE, et al. Coronary bypass surgery with or without surgical ventricular reconstruction. N Engl J Med 2009;360:1705-17.

68. Bonow RO, Maurer G, Lee KL, et al. Myocardial viability and survival in ischemic left ventricular dysfunction. $\mathrm{N}$ Engl J Med 2011;364:1617-25.

69. Jolicœur EM, Dunning A, Castelvecchio S, et al. Importance of angina in patients with coronary disease, heart failure, and left ventricular systolic dysfunction: insights from STICH. J Am Coll Cardiol 2015;66:2092-100.

70. Panza JA, Velazquez EJ, She L, et al. Extent of coronary and myocardial disease and benefit from surgical revascularization in ischemic $\mathrm{LV}$ dysfunction. J Am Coll Cardiol 2014;64:553-61. Erratum in: J Am Coll Cardiol 2014;64:1539.

71. Conte J. An indictment of the STICH trial: "True, true, and unrelated" J Heart Lung Transplant. 2010;29:491-6.

72. Mack MJ. Coronary artery disease: how should the STICH trial results affect clinical practice? Nat Rev Cardiol. 2011;8:427-8.

73. Fang JC. Underestimating medical therapy for coronary disease.again. N Engl J Med 2011;364:1671-3.

74. Hausmann H, Meyer R, Siniawski H, et al. Factors exercising an influence on recovery of hibernating myocardium after coronary artery bypass grafting. Eur J Cardiothorac Surg 2004;26:89-95.

75. Gorlin R, Klein MD, Sullivan JM. Prospective correlative study of ventricular aneurysm: mechanistic concept and clinical recognition. Am J Med 1967;42:512.
76. Loop FD, Efier DB, Navia JA, et al. Aneurysms of the left ventricle:survival and results of a ten-year surgical experience. Ann Surg 1973;178:399.

77. Favaloro RG, Effler DB, Groves LK, et al. Ventricular aneurysm--clinical experience. Ann Thorac Surg 1968;6:227-45.

78. Likoff W, Bailey CP. Ventriculoplasty: excision of myocardial aneurysm: report of a successful case. J Am Med Assoc 1955;158:915.

79. Dor V, Soab M, Coste P, et al. Left ventricular aneurysm: a new surgical approach. Thorac Cardiovasc Surg 1989;37:11-9.

80. Dor V, Sabatier M, Montiglio F, et al. Endoventricular patch reconstruction in large ischemic wall-motion abnormalities. J Card Surg 1999;14:46-52.

81. Cooley DA, Collins HA, Morris GGC, et al. Ventricular aneurysm after myocardial infarction. Surgical excision with use of temporary cardiopulmonary bypass. J Am Med Assoc 1958; 167:557-60.

82. Cooley DA, Frazier OH, Duncan JM, et al. Intracavitary are pair of ventricular aneurysm and regional dyskinesia. Ann Surg 1992;215:417-23.

83. Jatene $\mathrm{AD}$. Left ventricular aneurysmectomy. Resection or reconstruction. J Thorac Cardiovasc Surg 1985;89:321-31.

84. Faxon DP, Myers WO, McCabe CH, et al. The influence of surgery on the natural history of angiographically documented left ventricular aneurysm: The Coronary Artery Surgery Study. Circulation 1986;74:110-8.

85. Kawachi K, Kitamura S, Kawata T, et al. Hemodynamic assessment during exercise after left ventricular aneurysmectomy. J Thorac Cardiovasc Surg 1994;107:178-83.

86. Mickleborough LL, Maruyama H, Liu P, et al. Results of left ventricular aneurysmectomy with a tailored scar excision and primary closure. J Thorac Cardiovasc Surg 1994;107:690-8.

87. Dor V, Sabatier M, Di Donato M, et al. Efficacy of endoventricular patchplasty in large post-infarction akinetic scar and severe left ventricular dysfunction: comparison with a series of large dyskinetic scars. J Thorac Cardiovasc Surg 1998;116:50-9.

88. Bursi F, Enriquez-Sarano M, Nkomo VT, et al. Heart failure and death after myocardial infarction in the community: the emerging role of mitral regurgitation. Circulation 2005;111:295-301.

89. Otsuji Y, Handschumacher MD, Liel-Cohen N, et 
al. Mechanism of ischemic mitral regurgitation with segmental left ventricular dysfunction: three-dimensional echocardiographic studies in models of acute and chronic progressive regurgitation. J Am Coll Cardiol 2001;37:641-8.

90. Bonow RO, Carabello BA, Chatterjee K, et al. Focused update incorporated into the ACC/AHA 2006 guidelines for the management of patients with valvular heart disease: a report of the American College of Cardiology/American Heart Association Task Force on Practice Guidelines (Writing Committee to Revise the 1998 Guidelines for the Management of Patients With Valvular Heart Disease): endorsed by the Society of Cardiovascular Anesthesiologists, Society for Cardiovascular Angiography and Interventions, and Society of Thoracic Surgeons. Circulation 2008;118:e523-661.

91. Matthew MA, Romano MA, Bolling SF. Mitral valve repair as an alternative treatment for heart failure patients. Heart Fail Monit 2003;4:7-12.

92. McGee EC, Gillinov AM, Blackstone EH, et al. Recurrent mitral regurgitation after annuloplasty for functional ischemic mitral regurgitation. J Thorac Cardiovasc Surg 2004;128:916-24.

93. Hung J, Papakostas L, Tahta SA, et al. Mechanism of recurrent ischemic mitral regurgitation after annuloplasty: continued $\mathrm{LV}$ remodeling as a moving target. Circulation 2004;110:II85-90.

94. Matsunaga A, Tahta SA, Duran CM. Failure of reduction annuloplasty for functional ischemic mitral regurgitation. J Heart Valve Dis 2004;13:390-7; discussion 397-8.

95. Gelsomino S, Lorusso R, De Cicco G, et al. Five-year echocardiographic results of combined undersized mitral ring annuloplasty and coronary artery bypass grafting for chronic ischaemic mitral regurgitation. Eur Heart J 2008;29:231-40.

96. Tahta SA, Oury JH, Maxwell JM, et al. Outcome after mitral valve repair for functional ischemic mitral regurgitation. J Heart Valve Dis 2002;11:11-8; discussion 18-9.

97. Kuwahara E, Otsuji Y, Iguro Y, et al. Mechanism of recurrent/persistent ischemic/functional mitral regurgitation in the chronic phase after surgical annuloplasty: importance of augmented posterior leaflet tethering. Circulation 2006;114:I529-34.

98. Salgo IS, Gorman JH 3rd, Gorman RC, et al. Effect of annular shape on leaflet curvature in reducing mitral leaflet stress. Circulation 2002;106:711-7.

99. Borger MA, Murphy PM, Alam A, et al. Initial results of the chordal-cutting operation for ischemic mitral regurgitation.
J Thorac Cardiovasc Surg 2007;133:1483-92.

100. Rama A, Praschker L, Barreda E, et al. Papillary muscle approximation for functional ischemic mitral regurgitation. Ann Thorac Surg 2007;84:2130-1.

101. Robb JD, Minakawa M, Koomalsingh KJ, et al. Posterior leaflet augmentation improves leaflet tethering in repair of ischemic mitral regurgitation. Eur J Cardiothorac Surg 2011;40:1501-7; discussion 1507.

102.Jassar AS, Minakawa M, Shuto T, et al. Posterior leaflet augmentation in ischemic mitral regurgitation increases leaflet coaptation and mobility. Ann Thorac Surg 2012;94:1438-45.

103.de Varennes B, Chaturvedi R, Sidhu S, et al. Initial results of posterior leaflet extension for severe type IIIb ischemic mitral regurgitation. Circulation 2009;119:2837-43.

104.Langer F, Rodriguez F, Cheng A, et al. Posterior mitral leaflet extension: an adjunctive repair option for ischemic mitral regurgitation? J Thorac Cardiovasc Surg 2006;131:868-77.

105. Kincaid EH, Riley RD, Hines MH, et al. Anterior leaflet augmentation for ischemic mitral regurgitation. Ann Thorac Surg 2004;78:564-8; discussion 568.

106. Rothenburger M, Rukosujew A, Hammel D, et al. Mitral valve surgery in patients with poor left ventricular function. Thorac Cardiovasc Surg 2002;50:351-4.

107. Szalay ZA, Civelek A, Hohe S, et al. Mitral annuloplasty in patients with ischemic versus dilated cardiomyopathy. Eur J Cardiothorac Surg 2003;23:567-72.

108. Chen FY, Adams DH, Aranki SF, et al. Mitral valve repair in cardiomyopathy. Circulation 1998;98:II124-7.

109.Lachmann J, Shirani J, Plestis KA, et al. Mitral ring annuloplasty: an incomplete correction of functional mitral regurgitation associated with left ventricular remodeling. Curr Cardiol Rep 2001;3:241-6.

110. Bolling SF. Mitral reconstruction in cardiomyopathy. J Heart Valve Dis 2002;11:S26-31.

111. Silberman S, Klutstein MW, Sabag T, et al. Repair of ischemic mitral regurgitation: comparison between flexible and rigid annuloplasty rings. Ann Thorac Surg 2009;87:1721-6; discussion 1726-7.

112.Hausmann H, Siniawski H, Hotz H, et al. Mitral valve reconstruction and mitral valve replacement for ischemic mitral insufficiency. J Card Surg 1997;12:8-14.

113.Hausmann H, Siniawski H, Hetzer R. Mitral valve reconstruction and replacement for ischemic mitral insufficiency: seven years' follow up. J Heart Valve Dis 1999;8:536-42. 
114. Hetzer R, Delmo Walter EM. No ring at all in mitral valve repair: indications, techniques and long-term outcome.

Eur J Cardiothorac Surg 2014;45:341-51.

115.Hetzer R, Solowjowa N, Siniawski H, et al. Posterior

Cite this article as: Hetzer R, Javier MFDM, Wagner F, Loebe M, Javier Delmo EM. Organ-saving surgical alternatives to treatment of heart failure. Cardiovasc Diagn Ther 2021;11(1):213-225. doi: 10.21037/cdt-20-285 annulus shortening increases leaflet coaptation in ischemic mitral incompetence: a new and valid technique. Ann Cardiothorac Surg 2015;4:238-48. 